\title{
Paediatric inflammatory multisystem syndrome: What should we look out for in South Africa?
}

Despite the mayhem caused by COVID-19, children appear largely to have been spared. The disease in children is also more forgiving than in adults, and most children experience mild symptoms or are asymptomatic. ${ }^{[1-3]}$ While clinical presentation in children is similar to that in adults, with symptoms including fever, cough, sneezing, sore throat and malaise, progression to more severe lower respiratory tract disease is significantly less common. There have been reports of gastrointestinal manifestations in children, including diarrhoea and vomiting. ${ }^{[4]}$

Isolated reports of neonates presenting with unusual manifestations of sepsis have emerged. Although conflicting reports have indicated evidence for ${ }^{[5,6]}$ and against ${ }^{[7,8]}$ vertical transmission of the virus, it has not yet been proven to occur. ${ }^{[9]}$ New guidelines released by the Council for Medical Schemes suggest that healthy newborn infants of infected mothers do not require testing. COVID-19 infection has not been added as an indication for caesarean section. ${ }^{[10]}$

Severe disease in adults results from cytokine release syndrome (CRS) or 'cytokine storm'. There is a dysregulated release of cytokines and chemokines, especially interleukin (IL)-2, IL-6, IL-7, IL-10, tumour necrosis factor alpha, granulocyte colony-stimulating factor, interferon gamma inducible protein 10 , monocyte chemotactic protein 1 and monocyte inhibitory protein $1 \mathrm{~A} \cdot{ }^{[11]}$ This deleterious hyper-inflammatory state results from a maladaptation of both innate and adaptive immune responses, the first line of defence to protect individuals from viral infections. In a normal and healthy immune response, antiviral immunity would eradicate the pathogen. However, in a compromised immune system, this response can result in CRS. CRS in adults may potentially progress to acute respiratory distress syndrome (ARDS), multi-organ dysfunction and a widespread and potentially lethal hypercoagulable state. ${ }^{[12,13]}$

ARDS is significantly less common in children. However, one significant complication of COVID-19 has emerged in children. The first report of an atypical Kawasaki-like syndrome was reported in a child in Europe on 28 April 2020. ${ }^{[14]}$ This condition has since come to be known as COVID-19-associated paediatric multisystem inflammatory syndrome (PMIS). ${ }^{[15]}$ Case definitions have been formulated for this syndrome by the Royal College of Paediatrics and Child Health in the UK ${ }^{[16]}$ and the Centers for Disease Control in the USA. ${ }^{[17]}$ The details can be found in Tables 2 and 3, respectively, of the review article in this edition of SAMJ (pp. 864 - 868). ${ }^{[18]}$

Typical Kawasaki disease (KD), also referred to as mucocutaneous lymph node syndrome, ${ }^{[19]}$ is a rare disorder of unknown cause. ${ }^{[19]}$ Patients present with a constellation of clinical symptoms including persistent fever and mucocutaneous involvement such as conjunctivitis, changes in the tongue or oral cavity and oedema of the hands and feet, followed by desquamation of the epidermis, a rash and cervical lymph node involvement. ${ }^{[19]}$ The cardiac manifestations are related to a vasculitis leading to aneurysms of the coronary arteries in up to $20 \%$ of affected patients, although other blood vessels in the body may also be affected. Historically, KD has been seen most frequently in Asian countries, and despite exhaustive efforts to try to ascertain a cause for the condition, none has been found. ${ }^{[20]}$ There is therefore no confirmatory diagnostic test. ${ }^{[21,22]}$ The frequent association with an infectious pathogen has led to the hypothesis that $\mathrm{KD}$ is linked to an immune response to a specific antigen (innate and features of adaptive immune responses) in a genetically predisposed individual. ${ }^{[20]}$
PMIS presents in children after the acute phase of infection, evidenced in the majority of patients by the presence of SARS-CoV-2 antibodies and a negative polymerase chain reaction (PCR) test. ${ }^{[2,23]}$ In an attempt to determine the possible pathogenesis of the condition related to SARS-CoV-2, multiple theories have been postulated. Some indicate that, as in SARS-CoV-1, the presence of antibodies may increase viral entry into target cells ${ }^{[22]}$ or immune complexes may be deposited in tissues including coronary vessels. ${ }^{[22,23]}$ Furthermore, the cross-reactivity between a microbial antigen and host tissues, where certain proteins are shared (known as molecular mimicry), is also a possibility. ${ }^{[24]}$ Finally, McCrindle and Manlhiot ${ }^{[20]}$ posed the question whether SARS-CoV-2 may act as a co-stimulatory agent for the actual trigger in PMIS/KD.

An initial review of 10 cases of Kawasaki-like disease in Italy revealed a 30 -fold increase in such cases in the COVID-19 era compared with the 5 years preceding COVID-19. ${ }^{[23]}$ This review presents compelling indications for a potential association between PMIS and COVID-19. This report was followed by those from the USA (17 patients) ${ }^{[25]}$ France (2 reports: 21 patients ${ }^{[26]}$ and 16 patients $\left.{ }^{[27]}\right)$ and the UK (2 reports: 8 patients ${ }^{[28]}$ and 58 patients ${ }^{[22]}$ ), with additional reports being added on an ongoing basis. Clinical features of PMIS are reported to be similar to KD, although not always fulfilling all criteria. Patients usually present with persistent high-grade fever $\left(>38.5^{\circ} \mathrm{C}\right)$, shock, single- or multiorgan failure, skin or mucosal manifestations, and partial or complete fulfilment of the KD criteria. Other causes of sepsis as well as myocarditis are important to exclude.

Important differences have, however, been noted in the reports on PMIS, and must guide the identification of suspected cases presenting for medical care. The median age of presentation is older than that for classic KD. Patients with PMIS also seem more likely to develop severe disease, as evidenced by a higher rate of progression to shock, more severe lymphopenia and thrombocytopenia, high rates of myocardial dysfunction, and higher levels of inflammatory markers such as IL-6, serum ferritin and C-reactive protein. Despite the severity, the reported mortality rate remains at $2-4 \%$. This is encouraging, and supports the advantages to be gained from providing urgent treatment.

In a cohort of children with PMIS from France and Switzerland, ${ }^{[29]}$ an age range from 2 to 16 years was found. Nearly one-third of the children were known to have comorbidities, which included asthma and obesity. Most children had gastrointestinal symptoms. CRS and macrophage activation were presumed to be present in these children. Laboratory investigations yielded high levels of IL-6 (median $135 \mathrm{pg} / \mathrm{mL}$ ) and D-dimers (median $5284 \mathrm{ng} / \mathrm{mL}$ ). There was also a significantly elevated level of brain natriuretic peptide, which is thought to be released by cardiomyocytes as a result of ventricular stretching when blood volumes increase. In this study, ${ }^{[29]} 31$ of the 35 patients $(88 \%)$ had positive SARS-CoV-2 test results, either by PCR or serology. The authors noted that inflammation was not the only feature that might be contributing to coronary artery dilatation, and proposed that a different mechanism could be at play. One-third of the patients had a reduced cardiac ejection fraction. In managing these children, inotropic support was required in $80 \%$, and nearly one-third required extracorporeal membrane oxygen. Intravenous immunoglobins were used to treat all 35 patients, and remained the first line of treatment in all other reports describing management of 
patients with PMIS. One-third of the patients also received adjuvant steroid therapy. Pouletty et al. ${ }^{[27]}$ in a separate study, reported that $62 \%$ of their cohort required second-line treatment including further doses of immunoglobulin, corticosteroids or biological agents.

An important factor that may potentially have direct consequences for the South African (SA) population is the predominance of PMIS in patients of African ancestry (including African American and Afro-Caribbean). ${ }^{[22,26,29]}$ It is not known whether this is secondary to a genetic predisposition related to the presence of susceptibility or absence of protective genes, ${ }^{[20]}$ or due to other risk factors. What is clearly apparent from adult reports in the USA ${ }^{[30]}$ and the $\mathrm{UK}^{[31]}$ is a worse outcome in patients of African ancestry (and other minorities) who develop COVID-19. Again, it is not known whether genetic factors play a role or socioeconomic factors are the major contributors to the disproportionate mortality. Without knowledge of the potential risk in our own society, the diagnosis may be unnecessarily delayed.

In SA, there are currently no data on the number of children who have required hospital admission and intensive care. However, data from the USA suggest that children aged $<1$ year have a higher hospital and intensive care unit (ICU) admission rate than older children ${ }^{[3,32]}$ probably owing to an immature immune response that is ineffective at eradicating the viral pathogen. Additionally, other groups potentially at risk include children with underlying immune deficiencies (congenital, secondary to malignancy or administration of chemotherapy/radiation therapy, post-transplant due to high doses of glucocorticoids), underlying lung disease (e.g. asthma), cardiovascular disease, chronic kidney disease, diabetes mellitus and obesity. ${ }^{[33]}$ More than $80 \%$ of children admitted to ICUs in the USA were found to have comorbidities. ${ }^{[34]}$ The mortality rate for children admitted to a PICU is $5 \%$, which is significantly lower than that reported for critically ill adults.

Children are unlikely to be the source of transmission of SARS$\mathrm{CoV}-2$, as demonstrated in multiple studies where contact tracing has been effectively documented. ${ }^{[35-40]}$ This finding has bearing on continued 'lockdown', especially of children, and the number of unintended collateral damage consequences they experience. Many SA children were suffering long before the advent of COVID-19. Widespread poverty, lack of access to basic amenities and poor socioeconomic status have threatened their health for generations. These tribulations, in combination with a fractured healthcare system and a fragile economy, have proved to be lethal for the population group that is deemed to be the future of SA, the children of this country.

In summary, children are seldom infected with severe COVID19 and are a highly unlikely source of spread of the virus. If they do develop an exaggerated immune response, it may present as an atypical Kawasaki-like condition now referred to as PMIS. Cases have now been seen in SA, and a high index of suspicion is mandatory. If a child is suspected of having this condition, he or she must be referred for specialist care in a setting with high-care or intensive care facilities for prompt initiation of treatment in order to avoid the morbidity and mortality related to this disease.

\section{L Hendricks}

Institute for Cellular and Molecular Medicine, Department of Immunology, Faculty of Health Sciences, University of Pretoria, South Africa; and SAMRC Extramural Unit for Stem Cell Research and Therapy, Faculty of Health Sciences, University of Pretoria, South Africa candice_hendricks@outlook.com

\section{F Mustafa}

Institute for Cellular and Molecular Medicine, Department of Immunology, Faculty of Health Sciences, University of Pretoria, South Africa; SAMRC Extramural Unit for Stem Cell Research and Therapy; and Department of Paediatrics and Child Health, Faculty of Health Sciences, University of Pretoria, South Africa

\section{R J Green}

Department of Paediatrics and Child Health, Faculty of Health Sciences, University of Pretoria, South Africa

\section{S Pepper}

Institute for Cellular and Molecular Medicine, Department of Immunology, Faculty of Health Sciences, University of Pretoria, South Africa; and SAMRC Extramural Unit for Stem Cell Research and Therapy, Faculty of Health Sciences, University of Pretoria, South Africa

1. Liu W, Zhang Q, Chen J, et al. Detection of Covid-19 in children in early January 2020 in Wuhan, China. N Engl J Med 2020;382(14):1370-1371. https://doi.org/10.1056/NEJMc2003717

2. Dong Y, Mo X, Hu Y, et al. Epidemiology of COVID-19 among children in China. Pediatrics 2. Dong Y, Mo X, Hu Y, et al. Epidemiology of COVID-19 a
2020;145(6):e20200702. https:///doi.org/10.1542/peds.2020-0702

3. Bialek S, Gierke R, Hughes M, McNamara LA, Pilishvili T, Skoff T. Coronavirus disease 2019 in children - United States, February 12 - April 2, 2020. MMWR Morb Mortal Wkly Rep 2020;69(14):422-426.
https://doi.org/10.15585/mmwr.mm6914e4

4. Tullie L, Ford K, Bisharat M, et al. Gastrointestinal features in children with COVID-19: An observation of varied presentation in eight children. Lancet Child Adolesc Health 2020;7(20):19-20. https://doi.org/10.1016/S2352-4642(20)30165-6

5. Penfield CA, Brubaker SG, Limaye MA, et al. Detection of severe acute respiratory syndrome coronavirus 2 in placental and fetal membrane samples. Am J Obstet Gynecol MFM 2020 (epub 8 May 2020). https://doi.org/10.1016/j.ajogmf.2020.100133

6. Zeng H, Xu C, Fan J, et al. Antibodies in infants born to mothers with COVID-19 pneumonia. JAMA 2020;210(5040):1070-1071. https://doi.org/10.1001/jama.2020.4861

7. Chen H, Guo J, Wang C, et al. Clinical characteristics and intrauterine vertical transmission potential of COVID-19 infection in nine pregnant women: A retrospective review of medical records. Lancet 2020;395(10226):809-815. https://doi.org/10.1016/S0140-6736(20)30360-3

8. Li Y, Zhao R, Zheng S, et al. Lack of vertical transmission of severe acute respiratory syndrome . Li Y, Zhao R, Zheng S, et al. Lack of vertical transmission of severe acute respiratory syndrome
coronavirus 2, China. Emerg Infect Dis 2020;26(6):1335-1336. https://doi.org/10.3201/eid2606.200287 9. Zhu H, Wang L, Fang C, et al. Clinical analysis of 10 neonates born to mothers with 2019-nCoV 9. Zhu H, Wang L, Fang C, et al. Clinical analysis of 10 neonates born to mothers
pneumonia. Transl Pediatr 2020;9(1):51-60. https://oi.org/10.21037/tp.2020.02.06

10. Council for Medical Schemes. PMB definition guideline: COVID-19 version 3. 11 June 2020. https:// www.medicalschemes.com/files/PMB\%20Benefit\%20definition\%20guidelines/PMB_definition_ guideline-COVID-19_v3_11_June_2020.pdf (accessed 14 June 2020).

11. Diao B, Wang $C$, Tan $Y$, et al. Reduction and functional exhaustion of $T$ cells in patients with coronavirus disease 2019 (COVID-19). Front Immunol 2020;11:1-14. https://doi.org/10.3389/fimmu.2020.00827

12. Gattinoni L, Chiumello D, Rossi S. COVID-19 pneumonia: ARDS or not? Crit Care 2020;24(1):1-3. https://doi.org/10.1186/s13054-020-02880-z

13. Jose RJ, Manuel A. COVID-19 cytokine storm: The interplay between inflammation and coagulation. Lancet Respir Med 2020;8(6):e46-e47. https://doi.org/10.1016/\$2213-2600(20)30216-2

14. Woodyatt A. What is Kawasaki disease? The rare child syndrome might have link to Covid-19. CNN health, 28 April 2020. www.cnn.com/2020/04/28/health/kawasaki-disease-explainer-covid-19-intlscli/index.html (accessed 11 June 2020).

15. Deza Leon MP, Redzepi A, McGrath E, et al. COVID-19-associated pediatric multisystem inflammatory syndrome. J Pediatric Infect Dis Soc 2020;9(3):407-408 .https://doi.org/10.1093/jpids/piaa061

16. Royal College of Paediatrics and Child Health. Guidance: Paediatric multisystem inflammatory syndrome temporally associated with COVID-19. 2020. https://www.rcpch.ac.uk/sites/default/ files/2020-05/COVID-19-Paediatric-multisystem-inflammatorysyndrome-20200501.pdf (accessed 30 May 2020).

17. Centers for Disease Control and Prevention. Multisystem inflammatory syndrome in children (MIS-C) associated with coronavirus disease 2019 (COVID-19). 14 May 2020. https://emergency.cdc. gov/han/2020/han00432.asp?deliveryName=USCDC_511-DM28431 (accessed 14 May 2020).

18. Hendricks CL, Green RJ. COVID-19 in children: Should we be worried? S Afr Med J 2020;110(9):864868. https://doi.org/10.7196/SAMJ.2020.v110i9.15023

19. Park M. Pediatric Cardiology for Practitioners. 5th ed. Philadelphia: Mosby Inc., 2008:453-464.

20. McCrindle BW, Manlhiot C. SARS-CoV-2-related inflammatory multisystem syndrome in children. JAMA 2020;40(1):35-42. https://doi.org/10.1001/jama.2020.10370

21. Viner RM, Whittaker E. Kawasaki-like disease: Emerging complication during the COVID-19 pandemic. Lancet 2020;6736(20):19-20. https://doi.org/10.1016/S0140-6736(20)31129-6
paring

22. Whittaker E, Bamford A, Kenny J, et al. Clinical characteristics of 58 children with a pediatric inflammatory multisystem syndrome temporally associated with SARS-CoV-2. JAMA inflammatory multisystem syndrome temporally associ

23. Verdoni L, Mazza A, Gervasoni A, et al. An outbreak of severe Kawasaki-like disease at the Italian epicentre of the SARS-CoV-2 epidemic: An observational cohort study. Lancet 2020;6736(20):1-8. https://doi.org/10.1016/S0140-6736(20)31103-X

24. Raba AA, Abobaker A. Covid-19 and Kawasaki disease: An etology or coincidental infection. Pediatr Infect Dis J 2020;39(8):e213. https://doi.org/10.1097/INF.0000000000002779

25. Cheung EW, Zachariah P, Gorelik M, et al. Multisystem inflammatory syndrome related to COVID-19 in previously healthy children and adolescents in New York City. JAMA 2020;324(3):294-296. https:// doi.org/10.1001/jama.2020.10374

26. Toubiana J, Poirault C, Corsia A, et al. Kawasaki-like multisystem inflammatory syndrome in children during the covid-19 pandemic in Paris, France: Prospective observational study. BMJ 2020;369:m2094. https://doi.org/10.1136/bmj.m2094 
27. Pouletty M, Borocco C, Ouldali N, et al. Paediatric multisystem inflammatory syndrome temporally associated with SARS-CoV-2 mimicking Kawasaki disease (Kawa-COVID-19): A multicentre cohort. associated with SARS-CoV-2 mimicking Kawasaki disease (Kawa-COVID-19): A multice
Ann Rheum Dis 2020;79(8):999-1006. https://doi.org/10.1136/annrheumdis-2020-217960

28. Riphagen S, Gomez X, Gonzalez-Martinez C, Wilkinson N, Theocharis P. Hyperinflammatory shock in Riphagen S, Gomez X, Gonzalez-Martinez C, Wilkinson N, Theocharis P. Hyperinflammatory shock
in children during COVID-19 pandemic. Lancet 2020;6736(20):2019-2020. https://doi.org/10.1016/ S0140-6736(20)31094-1

29. Belhadjer Z, Méot M, Bajolle F, et al. Acute heart failure in multisystem inflammatory syndrome in children (MIS-C) in the context of global SARS-CoV-2 pandemic. Circulation 2020;142(5):429-436. https://doi.org/10.1161/CIRCULATIONAHA. 120.048360

30. Yancy CW. COVID-19 and African Americans. JAMA 2020;323(19):1891-1892. https://doi. org/10.1001/jama.2020.6548

31. Kirby T. Evidence mounts on the disproportionate effect of COVID-19 on ethnic minorities. Lancet Respir Med 2020;8(6):547-548. https://doi.org/10.1016/S2213-2600(20)30228-9

32. Parri N, Lenge M, Buonsenso D, Coronavirus Infection in Pediatric Emergency Departments (CONFIDENCE) Research Group: Children with Covid-19 in pediatric emergency departments in Italy. N Engl J Med 2020;383(2):187-190. https://doi.org/10.1056/NEJMc2007617

33. Edwards M. Coronavirus disease 2019 (COVID-19): Considerations in children. UpToDate, 2020. https://www.uptodate.com/contents/coronavirus-disease-2019-covid-19-considerations-in-children (accessed 10 May 2020).
34. Shekerdemian LS, Mahmood NR, Wolfe KK, et al. Characteristics and outcomes of children with coronavirus disease 2019 (COVID-19) infection admitted to US and Canadian pediatric intensive coronavirus disease 2019 (COVID-19) infection admitted to US and Canadian pediatric intensive
care units. JAMA Pediatr 2020 (epub 11 May 2020). https://doi.org/10.1001/jamapediatrics.2020.1948

35. Munro APS, Faust SN. Children are not COVID-19 super spreaders: Time to go back to school. Arch Munro APS, Faust SN. Children are not COVID-19 super spreaders: Time to go ba
Dis Child 2020;105(7):618-619. https://doi.org/10.1136/archdischild-2020-319474

36. Gudbjartsson DF, Helgason A, Jonsson H, et al. Spread of SARS-CoV-2 in the Icelandic population. N Engl J Med 2020;382(24):2302-2315. https://doi.org/10.1056/NEJMoa200610

37. Lavezzo E, Franchin E, Ciavarella C, et al. Suppression of COVID-19 outbreak in the municipality of Vo, Italy. medRxiv 2020 (epub 18 April 2020). https://doi.org/10.1101/2020.04.17.20053157

38. Mizumoto K, Omori R, Nishiura H. Age specificity of cases and attack rate of novel coronavirus disease (COVID-19). medRxiv 2020 (epub 13 March 2020). https://doi.org/10.1101/2020.03.09.20033142

39. Jing Q-L, Liu M-J, Yuan J, et al. Household secondary attack rate of COVID-19 and associated determinants. medRxiv 2020 (epub 15 April 2020). https://doi.org/10.1101/2020.04.11.20056010

40. National Institute for Public Health and the Environment, Ministry of Health, Welfare and Sport, Netherlands. Children and COVID-19. 2020. https://www.rivm.nl/en/novel-coronavirus-covid-19/ children-and-covid-19 (accessed 6 June 2020).

S Afr Med J 2020;110(9):832-834. https://doi.org/10.7196/SAMJ.2020.v110i9.15062 